\title{
Diminishing Atmospheric Carbon Monoxide fluxes as a Forecast of the New Planting Season in West Africa
}

\author{
Akinyemi M. L. \\ Department of Physics, Covenant University, Ota, Ogun State Nigeria \\ marvel.akinyemi@covenantuniversity.edu.ng
}

\begin{abstract}
This paper studied the variability of background Carbon Monoxide CO fluxes from 2000 to 2010 as released by satellite observatory system from the Measurement of Pollution in the Troposphere (MOPITT) instrument over the West African region, from latitude $2^{\circ} \mathrm{N}$ to $15^{\circ} \mathrm{N}$. From the twelve months of the year studied, the data for December and January to April followed a particular trend which was observed to be relevant in the forecasting of the following planting season over the region. The study revealed that the background CO fluxes averaged about 300ppbv in December and January and gradually reduces to about 220ppbv and 170ppbv in March and April respectively. This trend was observed in the ten years studied. It could be suggested thus that an average $35 \%$ to $45 \%$ decrease in December/January CO fluxes accumulation is a pointer to the beginning of the next planting season in the West African region. It was also observed that as the background $\mathrm{CO}$ flux dwindled, the locations of high $\mathrm{CO}$ concentrations due to fossil fuel combustions and other anthropogenic activities were more distinct in comparison to the rest of the region.
\end{abstract}

Keywords: Atmospheric Carbon Monoxide fluxes, Forecasting, Planting season

\section{INTRODUCTION}

Carbon monoxide (CO) has both natural and anthropogenic sources of emissions. A lot of studies in the past few decades had been done on both sources of emission although the focus seems to have tended more towards the anthropogenic sources than the natural sources. $\mathrm{CO}$ acts as a very significant chemical constituent in the troposphere, especially in the planetary boundary layer (PBL) as it is a precursor to a number of photochemical reactions that leads to secondary air pollutants (Logan et al., 1981, Arellano et al., 2004, Jacobson, 2000, Choi and Yoon-Seok, 2006). Carbon monoxide is part of the series of cycles of chemical reactions that form photochemical smog. It also reacts with oxides of nitrogen in the presence of sunlight to form low-lying ozone, sometimes called tropospheric ozone (Jacobson, 2000).

The net effect of $\mathrm{CO}$ on the ozone cycle can be summarized:

$$
\mathrm{CO}+2 \mathrm{O}_{2} \rightarrow \mathrm{CO}_{2}+\mathrm{O}_{3}
$$

The largest source of carbon monoxide worldwide is natural in origin, due to photochemical reactions in the troposphere that generate about $5 \times 10^{12}$ kilograms per year. Natural sources of $\mathrm{CO}$ include ocean surfaces, volcanoes, forest fires, and other forms of natural combustion. $\mathrm{CO}$ is produced through photochemical reactions on ocean surfaces and gets transported into the atmosphere (Bates et al., 1995; Jonson and Bates, 1996). According to researches, ocean surfaces are believed to be slightly supersaturated with $\mathrm{CO}$ to a certain degree and this super saturation leads to release of $\mathrm{CO}$ into the atmosphere to the tune of between 70 and 220

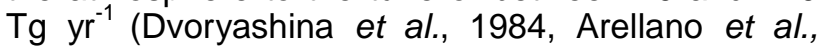
2004, Jacobson, 2000, Choi and Yoon-Seok 2006). Logan et al., (1981) however obtained a lower value of $40 \mathrm{Tg} \mathrm{yr}^{-1}$ for their own calculation. Many studies have been done on the distribution of background $\mathrm{CO}$ as a result of ocean-atmosphere interactions.

The anthropogenic sources of carbon monoxide emissions into the atmosphere are majorly from the exhaust of internal combustion engines which includes vehicles, electric power generators, lawn mowers, power washers etc. $\mathrm{CO}$ is also emitted from incomplete combustion of various other fuels such as firewood, coal, charcoal, oil, paraffin, propane, natural gas, and refuse. 


\section{METHODOLOGY AND DATA COLLECTION}

The analysis of the background Carbon Monoxide (CO) fluxes from 2000 to 2010 as released by satellite observatory system from the Measurement of Pollution in the Troposphere (MOPITT) instrument was done. Studies of the data for the twelve months of the year were done over the West African region from latitude $2^{\circ} \mathrm{N}$ to $15^{\circ} \mathrm{N}$. For the purpose of prediction, the $\mathrm{CO}$ anomaly was analyzed using some MathCAD2001 modeling functions. The four seasonal month distribution pattern, DecemberJanuary- February (DJF), March-April-May (MAM), June-July-August (JJA) and September-OctoberNovember (SON) were found to produce more accurate model of the raw data than the conventional January to December monthly array. Thus, December was coded as 0 month, while January to November was coded as 1 to 11 months respectively. $X$ represent the 12 months of the year which were coded 0 to $11, Y$ represent their corresponding $\mathrm{CO}$ anomaly/data.

\section{RESULTS AND DISCUSSION}

High accumulation of background $\mathrm{CO}$ along the West African region in December and January were observed in the eleven years studied from 2000 to 2010 (Figure 1). This study attributed this high concentration of background $\mathrm{CO}$ along the West African coast in December and January to various reasons other than anthropogenic sources and that generated from ocean-atmosphere interaction. One of such reasons is the north-south direction of zonal wind over the region namely Harmattan, which carries southward along with it a lot of particles from the Sahara desert. According to Akinyemi and Omotosho (2010), a maximum zonal wind flow of an average speed of $4.5 \mathrm{~ms}^{-1}$ was observed around latitudes $12^{\circ} \mathrm{N}$ in the West African region in the DJF season, while the direction of the flow was from north to south.

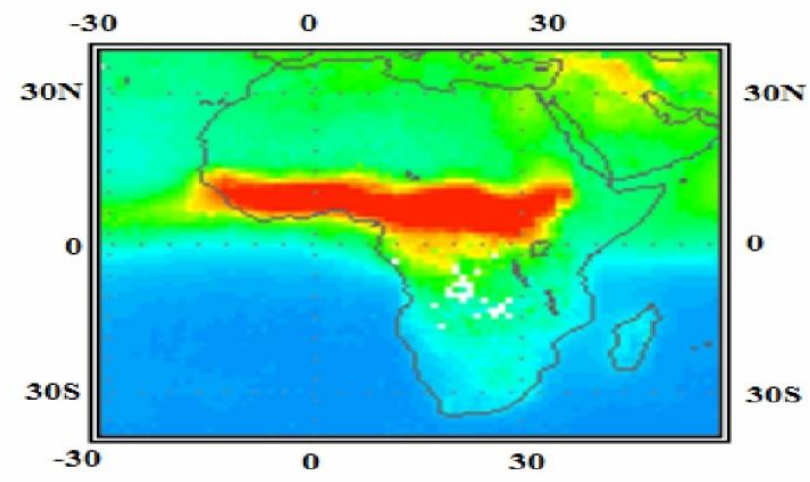

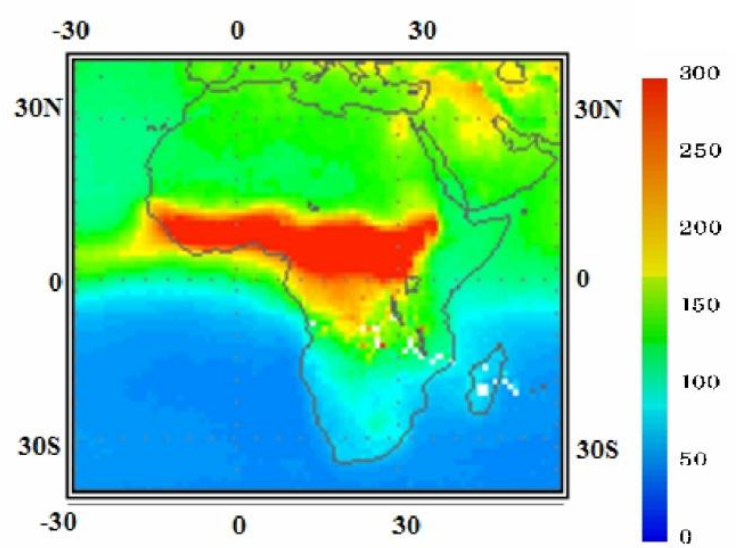

Fig 1: High Concentration CO Accumulation in December and January over West Africa as revealed by MOPITT

Besides, the period of DJF is the peak of the dry season which is usually characterized with lower humidity and higher temperature than normal along the West African coast. The accumulation of these dust particles, coupled with minimum precipitation due to the dry season and the presence of high temperature are suggested to be impetus for the increase in production of background $\mathrm{CO}$ concentration to the average of $300 \mathrm{ppbv}$ observed during this period over the region. This study revealed that the background $\mathrm{CO}$ concentration along the West African coast exceeds that of the adjourning ocean body, the Gulf of Guinea and the Atlantic by over $40 \%$ during the month of December and January. The $\mathrm{CO}$ concentration over the Gulf of Guinea was about 200ppbv, while that of the Atlantic was about 150ppbv. This further buttressed the fact that the high $\mathrm{CO}$ accumulation along the West African coast in DJF cannot be associated mainly with ocean-atmosphere interaction.

Also, since the high $\mathrm{CO}$ concentration was observed both over the urban high populated sections and the rural areas, it was an indication that the accumulation was not also due to anthropogenic sources. The map revealed that this accumulation of background $\mathrm{CO}$ extension was over 50 degrees on longitudinal scales, from about $16^{\circ} \mathrm{W}$ to as far eastward as longitude $35^{\circ} \mathrm{E}$. The $\mathrm{CO}$ accumulation in DJF season can thus be described as a synoptic scale phenomenon considering its widespread longitudinally. Synoptic scale atmospheric phenomenon encompasses regions for over a thousand miles and usually extends over a period of few days and sometimes weeks. This scale of $\mathrm{CO}$ accumulation in DJF is another pointer to the fact that the phenomenon is beyond an anthropogenic considering the fact that the level of industrialization 
and urbanization that can produce such high concentration of $\mathrm{CO}$ accumulation is virtually absent over that sub-region. Furthermore, the study revealed that as the accumulation of the background CO recedes significantly from $300 p p b v$ to about $170 \mathrm{ppbv}$ in the month of April, while the major anthropogenic sources of $\mathrm{CO}$ over the West African coast became more prominent on the map (Figure 2).

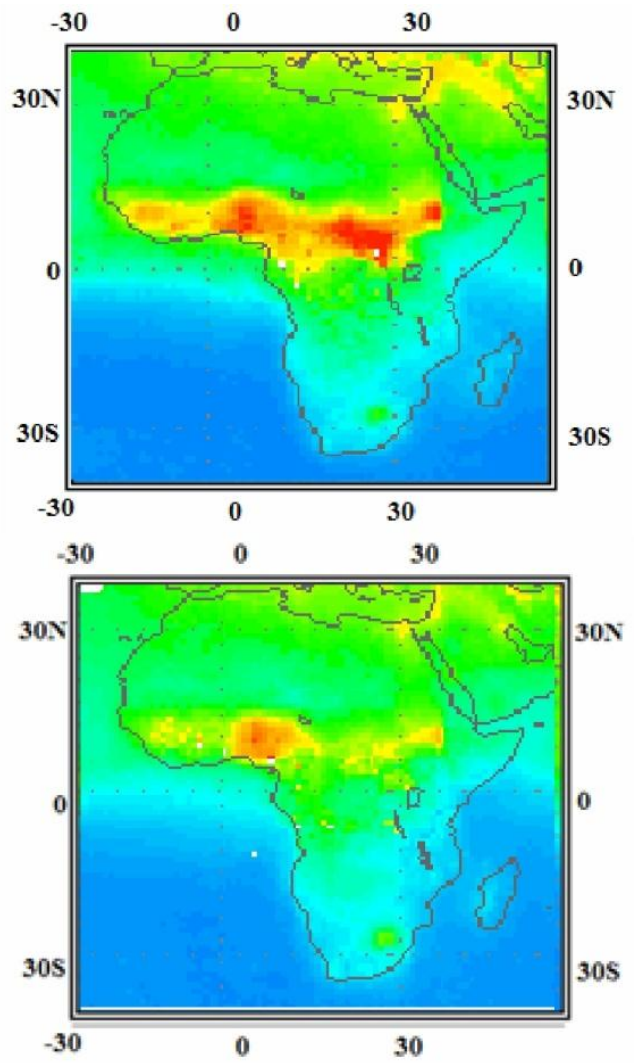

Fig 2: Waning CO Concentration in March and April over West Africa as revealed by MOPITT

For further analysis and prediction purpose, a model function for the $\mathrm{CO}$ data $\mathrm{H}(\mathrm{x})$ was defined and a range variable over which to graph the function was set by choosing the maximum and minimum values of the data set $X$ as the limit (equation 1). The unconventional month array of December to November was used as it returned a more accurate fit with the original data than the conventional January to December. Thus December was set as 0month, while January to November was assigned 1 to 11 month.

$$
H(x):=E_{0} \cdot e^{E_{1} \cdot x}+E_{2}
$$$$
\mathrm{x}:=\min (\mathrm{X}) . . \max (\mathrm{X})
$$

The raw data and the obtained modeled values for the $\mathrm{CO}$ anomaly were graphed as shown in Figures $3(a)$. The correlation coefficient of the measured data with the model was computed as 0.86

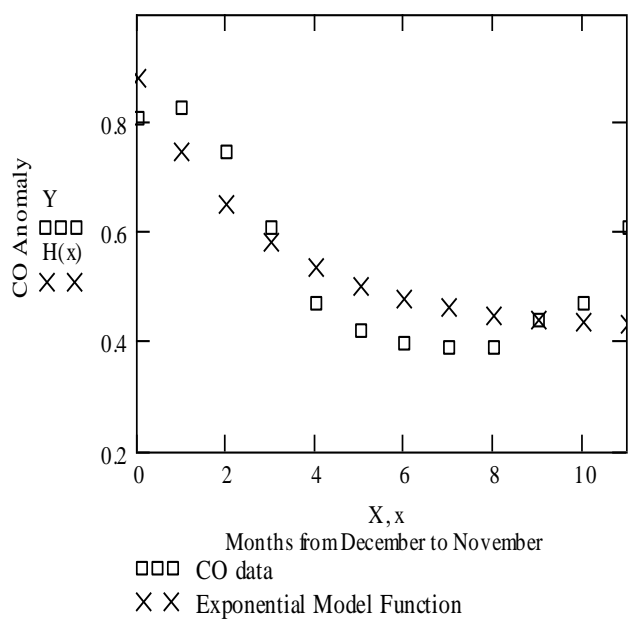

Fig 3a: Monthly Variation of $\mathrm{CO}$ anomaly in West Africa

Double Exponential Modeling

Also a double exponential model of $\mathrm{CO}$ anomaly was carried out. A model function $\mathrm{G}(\mathrm{x})$ was defined using MathCAD as shown below in equations (3)

$$
\mathrm{G}(\mathrm{x}):=\frac{\mathrm{D}(\mathrm{x})}{2}
$$$$
\mathrm{D}(\mathrm{x}):=(2 \mathrm{E}) \cdot \mathrm{e}^{(2 \mathrm{E}) \cdot 1^{\mathrm{x}}}+(2 \mathrm{E}) 2
$$

The correlation coefficient of the measured data with the double exponential model was computed as 0.82. The Observed $\mathrm{CO}$ anomaly, the first and the second model functions were all plotted together as shown in Figure 3b. For the purpose of comparison the same analysis was carried out for the total CO concentration data (Figure 4). 


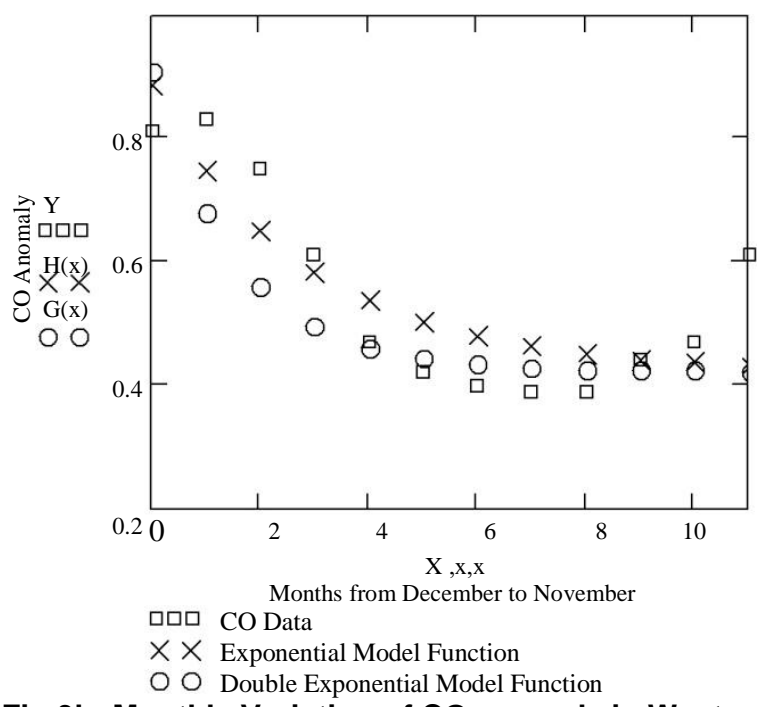

Fig 3b: Monthly Variation of CO anomaly in West Africa

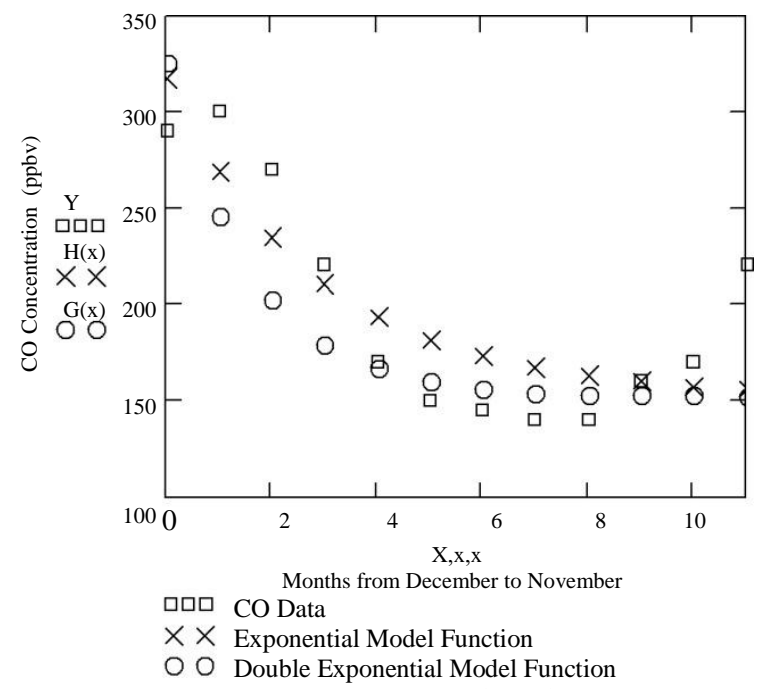

Fig 4: Monthly Distribution of $\mathrm{CO}$ Concentration in West Africa

For the monthly $\mathrm{CO}$ distribution, the correlation coefficients of the measured data with both the single and double exponential models were respectively 0.85 and 0.82 .

The models and the observed $\mathrm{CO}$ data revealed that background $\mathrm{CO}$ seasonal concentration was maximum between December and February, while lower level $\mathrm{CO}$ concentrations were recorded from April all through to October. The $\mathrm{CO}$ fluxes accumulation in December/January exceeded that of April by an average of $45 \%$. The CO concentration for December/January was about 300ppbv while that of April was about 170ppbv and recorded a minimum value of about 145ppbv in JJA. This trend was observed in the eleven years studied. It could be suggested thus that the almost fifty percent reductions in background $\mathrm{CO}$ in April is a sign of a favorable atmospheric conditions for the beginning of a new agricultural season. The study observed that from April all through to October, the trend in background $\mathrm{CO}$ was on the decrease, which further indicates the favorable atmospheric composition for agricultural production in the West African region.

\section{CONCLUSION}

This study revealed that with other parameters such as soil moisture content and temperature in place, a limit background $\mathrm{CO}$ concentration of maximum value 170ppbv is an indicator for the beginning of a new sustainable agricultural production season in West Africa. Higher concentration value of background CO may not be favorable to planting season as it may induce low $\mathrm{pH}$ precipitation which will reduce the agricultural yields due to its acidity. Normally, rainwater has a $\mathrm{pH}$ of 6.5 , making it slightly acidic, but the presence of certain chemical substances in the atmosphere during the raining season can further lower the $\mathrm{pH}$ of rainwater to as low as 3.5 making it significantly acidic and unsuitable for high agricultural yield.

\section{REFERENCES}

Akinyemi M. L. and T. V. Omotosho, 2010. Signature of Atmospheric Dynamics on Surface Ozone Variability in Nigeria. Canadian Journal of Pure and Applied Science VOL. 4(3), pp. 1289-1292

Arellano A. F., P. S. Kasibhatla, L. Giglio, G. R. van der Werf, J. T Randerson, 2004. Top-down estimates of global CO sources using MOPITT measurements, Geophysical Research Letters, VOL. 31, L01104, 5 PP., doi:10.1029/2003GL018609

Bates T. S., K. C. Kelly, J. E. Johnson and R. H. Gammon 1995. Regional and seasonal variations in the flux of oceanic carbon monoxide to the atmosphere Journal of Geophysical Research, VOL. 100, NO. D11, PP. 23,093-23,101, 1995 doi:10.1029/95JD02737

Choi, Sung-Deuk, and Yoon-Seok Chang 2006. Carbon monoxide monitoring in Northeast Asia using MOPITT: Effects of biomass burning and regional pollution in April 2000, Atmosphere Environment, 40(4), 686 
Am. J. Sci. Ind. Res., 2012, 3(4): 198-202

Dvoryashina E.V., V.I. Dianov-Klokov and L.N. Yurganov, 1984. "Variations of the Content of Carbon Monoxide in the Atmosphere in the Period from 1970 to 1982", Izvestiya, 20, 27-33.

Jacobson, M. Z. 2000. Fundamental of Atmospheric Modeling, Cambridge Univ. Press, pp. 352 -358.
Johnson, J. E., and T. S. Bates 1996, Sources and sinks of carbon monoxide in the mixed layer of the tropical South Pacific Ocean, Global Biogeochem Cycles, 10(2), 347

Logan, J. A., M. J. Prather, S. C. Wofsy, and M. B. McElroy, 1981. Tropospheric chemistry: A global perspective, J. Geophys. Res., 86, 7210-7254 